\title{
Performance of the Working Length Determination using Cone Beam Computed Tomography, Radiography and Electronic Apex Locator, in Comparisons to Actual Length
}

\author{
Cihan Yildirim, ${ }^{1}$ Ali Murat Aktan, ${ }^{2,}{ }^{*}$ Emrah Karataslioglu, ${ }^{1}$ Fatih Aksoy, ${ }^{1}$ Ozlem Isman, ${ }^{2}$ and Emre
}

Culha ${ }^{3}$

${ }^{1}$ Department of Endodontics, Faculty of Dentistry, Gaziantep University, Gaziantep, Turkey

${ }^{2}$ Department of Dentomaxillofacial Radiology, Faculty of Dentistry, Gaziantep University, Gaziantep, Turkey

${ }^{3}$ Department of Endodontics, Faculty of Dentistry, Zirve University, Gaziantep Turkey

Corresponding author: Ali Murat Aktan, Department of Dentomaxillofacial Radiology, Faculty of Dentistry, Gaziantep University, Gaziantep, Turkey. Tel: +90-5327074499, Fax: +90-3423610346, E-mail: alimurataktan@yahoo.com

Received 2015 July 01; Revised 2015 August 28; Accepted 2015 September 12.

\begin{abstract}
Background: Determination of the working length $(\mathrm{WL})$ is important on the success of the endodontic treatment. There are several techniques used for the determination of endodontic WL, whereas new technologies may include clinical practice and, therefore, they should be investigated.

Objectives: The goal of the cone beam computed tomography (CBCT) based investigation was to compare determination of the WL performance of the electronic apex locator (EAL), CBCT and digital radiography.

Materials and Methods: Totally, 30 single rooted, freshly extracted permanent teeth were included. Root canal WL measurements were performed using actual length (AL), EAL, digital radiograph and CBCT. The percentages of $\pm 0.5 \mathrm{~mm}$ measures to the AL, among the experimental groups, were compared by using Chi-Squared and Fischer Exact tests. The statistical significance was determined at $\mathrm{P}<0.05$.

Results: The CBCT was the most accurate method to evaluate the root canal WL, with accuracy of $70 \%$. Accuracy for the apex locator and periapical radiograph were $40 \%$ and $30 \%$, respectively.

Conclusion: The CBCT may be safe to use in determining root canal WL. Because lower radiation dose, a pre-existing CBCT can be useful to detect the root canal WL more precisely.
\end{abstract}

Keywords: Cone-Beam Computed Tomography, Root Canal Therapy, Endodontics

\section{Background}

Protecting the original form of the narrowest diameter of the apical foramen is essential for obtaining a good apical obturation and prevent apical extrusion of root canal content(1). Researches have shown that root canal content, forced into the periapical tissue, may cause postoperative pain (2) and failed root canal treatment. Although 0-2 mm distance is acceptable between radiographic apex and the obturation material (3), exact determination of the apical constriction is crucial.

Digital periapical radiographs (PRs) and electronic apex locators (EAL) are integral parts of working length (WL) measurement $(4,5)$. While PR is used for the determination of the radiographic apex, EAL is used to measure the root canal length to apical constriction, not the radiographic apex. A Root ZX mini (J. Morita Corp., Tokyo, Japan), which is known to be one of the most reliable devices for determining WL, was employed to measure the electronic length of the root. The principles of EAL can be explained by Ohm's law, summarized as voltage/current = resistance. . Ohm's law is changed to voltage/current = impedance in alternative current (AC) (6). The observation that the ratio between two electrical impedances (oral mucosa and periapical tissue) decreases, as the file tip approaches the apical foramen, led to the development of the ratio method for WL determination (7). Digital receptors for intraoral dental radiography have been available during the last decades. An increasing number of general dental practitioners have preferred them to digital imaging. The charge-coupled device or complementary metal oxide semiconductor (CCD/CMOS) sensor systems and the photostimulable storage phosphor (PSP) systems are used as a digital receptor. The main advantages of these systems are fewer errors in the image, fewer environmental problems, time saving, dose reduction for the patient, patient friendly usage and the dynamic digital imagery (8). However, there are disadvantages and limitations to these two 
methods. The interpretation of PRs is often difficult. Because PRs are two-dimensional (2-D) images, superimposition of anatomical structures and the curvatures in the buccolingual direction make it difficult to obtain a correct diagnosis (9). In addition, apical constriction cannot be detected in PRs, to determine a true WL.

The WL measurement accuracy of recently used EALs varies over a wide range (58.7-97.6\%), depending on the device, irrigation solution, tooth type (anterior, bicuspid, or molar) and file diameter (10-13). Nevertheless, EALs are more exact than periapical radiograms in determining the apical foramen (10).

To use three-dimensional (3-D) imaging in lower doses, cone beam computed tomography (CBCT) is increasingly becoming popular in dentistry, although it was first developed for use in angiography (14). Its imaging technique is based on a cone-shaped X-ray beam that is centered on a flat panel detector, and the X-ray tube performs one rotation around the object, producing a series of 2-D images. The 2-D images are reconstructed in a 3-D data set, using an algorithm developed by Feldkamp et al. (15). The CBCT was further developed to have lower exposure doses (16, 17), with a higher resolution and more compact than conventional computed tomography, which make them more practical in dentistry (18). Nowadays, CBCT is used quite widely in oral surgery and implantology. The CBCT may allow for diagnosis and possible indications in the field of endodontics and is used in detection of apical periodontitis, endodontic surgery, dental trauma, evaluation of root canal anatomy and morphology, root resorption, diagnosis of vertical root fractures and assessment of the outcome of endodontic treatment (19).

\section{Objectives}

In the present study, CBCT, PR and EAL were compared to determine the WL, in vitro. In addition, differences in WL measurement among the three methods, when measuring actual root canal length, were determined.

\section{Materials and Methods}

The present investigation used 30 single-rooted, intact, permanent teeth that had been extracted for periodontal or orthodontic purpose. The teeth with immature or wide apices, restorations, fractured teeth, root resorption, calcifications, or previous endodontic treatments were not included in the research. They were also examined radiographically for single canal presence. After extraction, they were kept in distilled water, up to use.

Endodontic access cavities were created with a highspeed hand-piece. Pulp canal debris were removed and a straight canal entrance was obtained from the coronal part of the canal, with a \#3 Gates-Glidden bur (Thomas FFDM Pneumat, Bourges, France). Pulp canals were cleaned with $5 \mathrm{~mL}$ of $3 \%$ sodium hypochlorite $(\mathrm{NaOCl})$ solution. The canal patency was verified with insertion of a size \#10 KFile (Kerr Italia S.R.L, Scafati, Italy) to the apex. After completion of orifice opening and verification of canal patency, WL measurements were performed, as follows:

\subsection{Actual Length Measurement}

To measure the actual length $(\mathrm{AL})$ as a gold standard in the present study, a standard-size \#10 or \#15 K-File (Kerr Italia S.R.L, Scafati, Italy) was inserted into the canal, until the tip can be seen through the major foramen. Then, the file was reinserted, until its tip was seen under a magnifying glass $(\times 2.5)$, at the level of the coronal-most boundary of the major foramen. The rubber stopper was set and the distance determined, with a digital caliper and detected as the AL.

\subsection{Radiographic Working Length Measurement}

For each tooth, two radiographs were taken using the parallel technique. These images were obtained with a

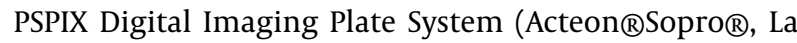
Ciotat, France). The first radiograph was taken to determine the radiographic tooth length, described as the distance between the coronal reference and the radiographic apex. The second radiograph was taken to determine the radiographic working length (RWL). For RWL determination, a size \#10 or \#15 K-File (Kerr Italia S.R.L, Scafati, Italy) with a rubber stopper was inserted into the canal, and then $1 \mathrm{~mm}$ was subtracted from the gauging, registered as the radiographic tooth length and recorded as the RWL (Figure $1 \mathrm{~A})$.

\subsection{Cone Beam Computed Tomography Working Length Mea- surement}

The CBCT images were obtained by a trained dentomaxillofacial radiologist, using a Planmeca ProMax 3D Mid (Planmeca Oy, Helsinki, Finland) using the voxel size of 0.5 $\mathrm{mm}$, field of view (FOV) $50 \times 80 \mathrm{~mm}$ and high resolution. The working model was placed on an adjustable tripod, to standardize the imaging.

First, each root canal was located vertically, to illustrate, whenever possible, the entire canal length in a single view (Figure $1 \mathrm{~B}, 1 \mathrm{C}, 1 \mathrm{E}$ and $1 \mathrm{~F}$ ). The repetition of this process was done to acquire buccolingual and mesiodistal sections of each tooth and the most complete view of the root-canal pathway was chosen. A reference point was determined from the occlusal plane, following the visible 

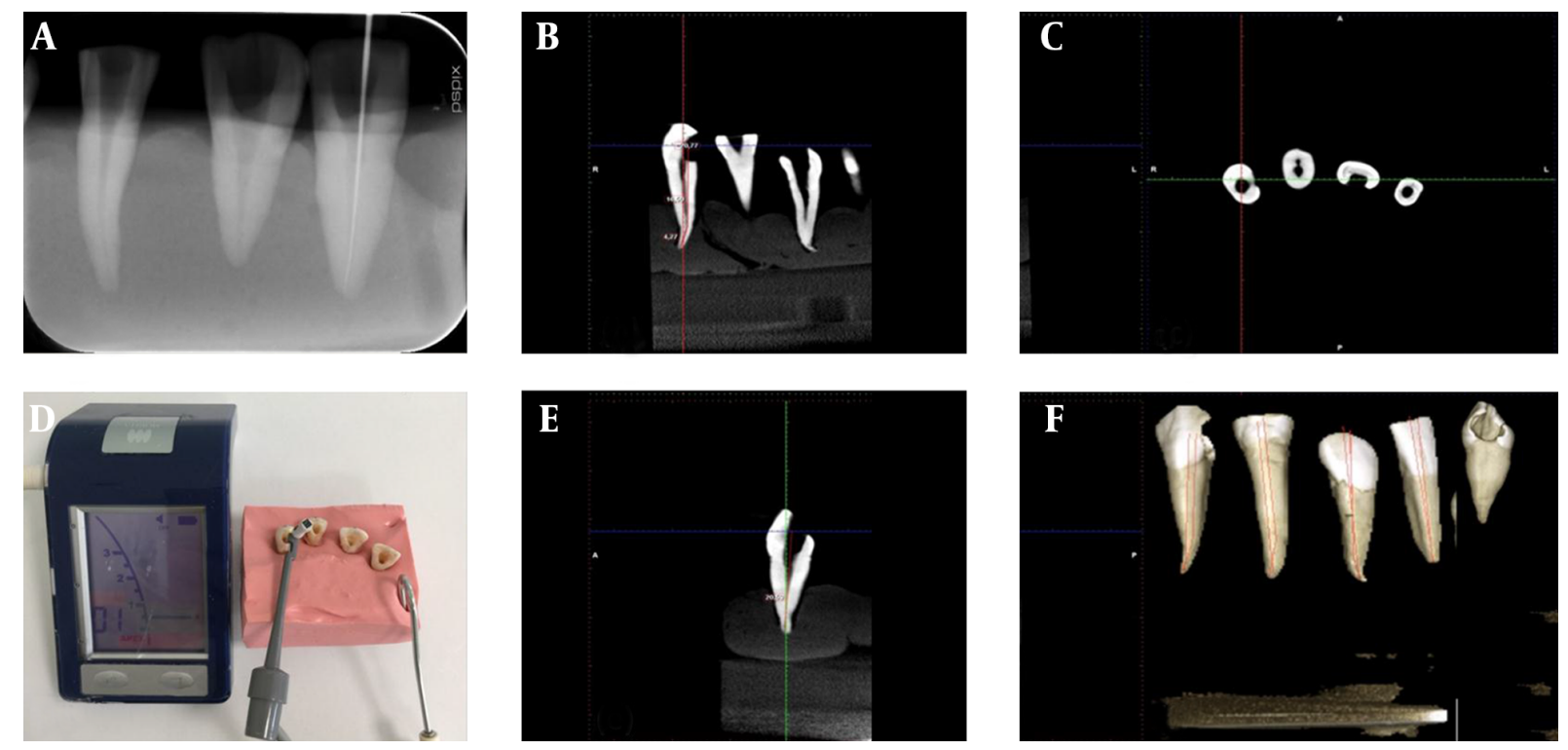

Figure 1. Working length measurements; A, Digital radiography; B, Cone beam computed tomography images including coronal section; C, Axial section; D, Electronic apex locators; E, Sagittal section; F, 3-D image of the teeth.

canal curvature in the respective CBCT slice. This measurement was recorded as the CBCTWL. All images were viewed in the same format, as the saturation/contrast adjustment. All procedures were performed using a Planmeca Romexis Viewer (Planmeca Oy, Helsinki, Finland).

\subsection{Electronic Working Length Measurement}

A Root ZX mini (J. Morita Corp., Tokyo, Japan), which is known to be one of the most reliable methods for determining WL, apex locator was employed to measure the electronic length of the root. The principles of EAL can be explained by Ohm's law (9) Ohm's law is expressed as voltage/current $=$ resistance. Ohm's law is changed to voltage/current = impedance, in AC. The observation that the ratio between two electrical impedances (oral mucosa and periapical tissue) decreases, as the file tip approaches the apical foramen, led to the development of the ratio method for WL determination (8)

Alginate (Hydrogum5, Zhermack, Badia Polesine, Italy) was put into a box and all teeth were placed in it. The lipclip electrode of the apex locator was inserted in the alginate. For electronic measures of the canal length, a size \#10 or \#15 K-File (Kerr Italia S.R.L, Scafati, Italy) was inserted into the root canal and connected to the apex locator. The WL was determined by producer's instructions and was recorded as the EWL (Figure 1D).

All measures related to CBCT and radiography were examined by the one radiologist experienced in CBCT applications (AMA) and digital periapical radiography (OI) and all measures related to EAL (EK) and AL (EC) were examined by the one endodontist, experienced in endodontics, and they were blinded to previous measurements.

\subsection{Statistical Analysis}

The intraclass correlation coefficient (ICC) was used for the determination of the intraobserver agreement for each methods. Shapiro Wilk test was used for the determination of normality $(\mathrm{P}>0.05)$. The comparison of the means of the groups was assessed using repeated measure ANOVA and post hoc Dunnett tests were performed for multiple comparisons of the groups. To compare the percentage of accuracy, binominal test was performed. The correlation between the actual root canal length and the EWL, RWL and CBCT measurements were evaluated, using the Pearson correlation coefficient. The confidence interval was determined at $\mathrm{P}<0.05$. The SPSS ver. 20 software (IBM Corp., Armonk NY, USA) was used to perform statistical analyses.

\section{Results}

The ICC of the numerical values related to the AL, CBCTWL, EWL and RWL measurements were found as 0.916, $0.869,0.852$ and 0.801 , respectively. The results of the current study revealed a statistically significant difference in the success of measurements among the groups, as compared to the $\mathrm{AL}(\mathrm{P}<0.05)$. While $21(70 \%)$ of the 30 teeth were in the range of $0.5 \mathrm{~mm}$, when using the CBCTWL measurement, for using EWL and RWL measurements, 40\% and 
$30 \%$, respectively, were in the $0.5 \mathrm{~mm}$ range (Table 1 ). Binomial test showed that there were statistically significant differences between the groups $(\mathrm{P}=0.001)$.

There were no statistically significant differences among the AL, EWL, RWL and CBCT measurements ( $\mathrm{P}>$ 0.05) (Table 2). Multiple comparisons of the WL measurement methods showed that mean difference to the $\mathrm{AL}$ were $0.64 \mathrm{~mm}$ for EWL, $0.65 \mathrm{~mm}$ for RWL and $0.20 \mathrm{~mm}$ for CBCT (Table 3). High correlations were found between the AL and the EAL, PR and CBCT measurements (Table 4).

\section{Discussion}

The accuracy of the CBCTWL determination was 70\% for $0.5 \mathrm{~mm}$ and mean difference to the AL was $0.20 \mathrm{~mm}$. This accuracy was found to be the greatest, compared with the PR and EAL, of 40\% and 30\%, respectively. Since distances < $0.5 \mathrm{~mm}$ are negligible in clinical conditions (20), this study shows that CBCT can be used to determine WL confidently. Previous studies have shown that CBCT is highly reliable in distance measurement (21). Connert et al. (20) found a $0.41 \mathrm{~mm}$ difference between CBCT and AL, which is in accordance with the present study. In addition, the present study found a high correlation among AL, EAL, PR and CBCT. In contrast to this, Lucena et al. (22) found EAL more reliable than CBCT.

The mean difference between CBCT and AL was $0.2 \mathrm{~mm}$. Previous studies have reported a high accuracy between CBCT measurements and AL, with mean differences of 0.41 $\mathrm{mm}$ and $0.46 \mathrm{~mm}$, which were in accordance with the present study $(20,23)$. Tchorz et al. (24) used molar teeth in their study and found a $0.32 \mathrm{~mm}$ difference between CBCT and AL measurements. In the present study, the mean difference was smaller $(0.2 \mathrm{~mm})$ than in previous studies. Also, in contrast to previous studies, the one-rooted teeth, used in this study, may have resulted in less difference between CBCT measurements and AL. Connert et al. (20) made CBCT measurements by marking up a single line between foramen and cusp tip. Lucena et al. (22) used a multiple-line tracing tool for the curved canals. Connert et al. (20) reported that drawing the canal using multiplelines to follow the canal line could lead to more precise measurements.

In the present study, calculation of the AL at the major foramen was done by inserting the file until its tip was seen under a magnifying glass $(\times 2.5)$, at the level of the coronalmost boundary of the major foramen. Ozsezer et al. (25) subtracted the file $0.5 \mathrm{~mm}$, after viewing the file at the end of the canal. In contrast, Lucena et al. (22) and Connert et al. (20) preferred to calculate the AL with the file tip flush with the foramen.
The $\pm 0.5 \mathrm{~mm}$ to the apex is thought as the most reasonable distance for radiographic locations (26). Real et al. (9) used a clinical distance of $\pm 1.0 \mathrm{~mm}$ to the cementodentinal junction. However, Lucena et al. (22) took into account \pm 0.5 and $\pm 1.0 \mathrm{~mm}$ of the AL and concluded that the greater the percent of proper measurements, the greater the performance. In the current research, measurements obtained were within the acceptable limits of $\pm 0.5 \mathrm{~mm}$.

Since there is variation in apical root morphology (27), it is impossible to establish the location of the apical canal constriction, with complete certainty. The EALs are most commonly used to measure the WL, with accuracy of 50$93.3 \%$, using a tolerance of $\pm 0.5 \mathrm{~mm}$ from the ALs, in the normal periapical conditions $(28,29)$. However, several conditions negatively affect the accuracy of EALs, such as tooth length (30), enlarged apical foramina (31), ingredients (solutions, pastes, etc.) used in the root canal $(32,33)$, brand of device (31), type of tooth (11) and file size (34).

Radiographic measurement and electronic measurement each have disadvantages and it has been advised to use a combination of the two (35). The CBCT, with the advantages of less radiation and the possibility of 3-D evaluation, showed a high correlation with $\mathrm{AL}$, and the mean difference between AL and CBCT measurements was only 0.20 $\mathrm{mm}$. In accordance with the present study, Liang et al. (23) found CBCT-based root-canal length measurements are accurate and reliable, when compared with a gold standard, as actual length. In addition, Janner et al. (36) reported that an existing CBCT is as successful as an EAL. Connert et al. (20) found $69 \%$ accuracy with the CBCT, compared with $\mathrm{AL}$, and concluded that CBCT images can be used to accurately determine $\mathrm{WL}$, in all groups of teeth and in canals. In contrast to these findings, Lucena et al. (22) showed that EAL measurements were more accurate than CBCT to determine WL. In the current research, no differences among AL, CBCT, EAL and PR measurements were found; however, there was a high correlation between CBCT and AL measurements. Twenty-one of the 30 teeth were in the range of the acceptable $\pm 0.5 \mathrm{~mm}$ and the average difference was found as $0.20 \mathrm{~mm}$.

As a result of the present study, since CBCT based WL measurements are consistent with the other techniques, it could be safe to use for the determination of root canal WL. However, As Low As Reasonably Achievable (ALARA) principles (concerning radiation dose) should be considered, because of high radiation dose of the CBCT for determination of WL or any endodontic purpose, while a preexisting CBCT could be used to detect the canal path WL, more precisely. Further studies related to determination of WL, using CBCT, are needed to increase their usage in endodontics, clinically. 
Table 1. True or False Distribution of Electronic Apex Locators, Radiograph and Cone Beam Computed Tomography Measurements, According to the Actual Length ${ }^{\mathrm{a}, \mathrm{b}}$

\begin{tabular}{lccc}
\hline & True & False & Total \\
\hline EAL & $12(40)^{\mathrm{A}}$ & $18(60)$ & 30 \\
Radiograph & $9(30)^{\mathrm{B}}$ & $21(70)$ & 30 \\
CBCT & $21(70)^{\mathrm{B}}$ & $9(30)$ & 30 \\
\hline
\end{tabular}

Abbreviations: $\mathrm{CBCT}$, Cone beam computed tomography; EAL, electronic apex locator; RWL, radiographic working length.

${ }^{\mathrm{a}}$ Values are expressed as No. (\%).

${ }^{\mathrm{b}} \mathrm{A}$ and $\mathrm{B}$ represents the groups with statistically similar results separately.

Table 2. Means and Standard Deviations of the Working Length Measures in Millimeter

\begin{tabular}{lcccc}
\hline & $\mathbf{N}$ & Mean, mm & Standard Deviation & Minimum \\
\hline Actual length & 30 & 21.797 & 1.583 & 17.750 \\
EWL & 30 & 21.152 & 1.692 & 17.130 \\
RWL & 30 & 21.143 & 1.528 & 16.930 \\
CBCTWL & 30 & 21.594 & 1.565 & 23.960 \\
\hline
\end{tabular}

Abbreviations: CBCTWL, cone beam computed tomography working length; EWL, electronic working length; RWL, radiographic working length.

Table 3. Mean Difference of EWL, RWL and CBCTWL to the Actual Length ${ }^{\mathrm{a}, \mathrm{b}}$

\begin{tabular}{|c|c|c|c|c|c|c|}
\hline \multirow[t]{2}{*}{ Group } & \multirow[t]{2}{*}{ Group } & \multirow[t]{2}{*}{ Mean Difference, mm } & \multirow[t]{2}{*}{ Standard Error } & \multirow[t]{2}{*}{ P Value } & \multicolumn{2}{|c|}{ 95\% Confidence Interval } \\
\hline & & & & & Lower Bound & Upper Bound \\
\hline EWL & $\mathrm{AL}$ & 0.6450 & 0.40949 & 0.735 & -1.3197 & 0.6297 \\
\hline RWL & AL & 0.6543 & 0.40949 & 0.719 & -1.3290 & 0.6203 \\
\hline CBCTWL & AL & 0.0220 & 0.40949 & 1 & -0.9967 & 0.9527 \\
\hline
\end{tabular}

Abbreviations: AL, actual length; CBCTWL, cone beam computed tomography working length; EWL, electronic working length; RWL, radiographic working length.

${ }^{a}$ Based on observed means.

${ }^{\mathrm{b}}$ Dunnett t-tests treat one group as a control and compare all other groups against it.

Table 4. Correlation Between Actual Length and the Electronic Working Length, Radiographic Working Length and Cone Beam Computed Tomography Working Length

\begin{tabular}{lcccc}
\hline & & EWL & RWL & \\
\hline \multirow{2}{*}{ Actual length } & Pearson Correlation & $0.900^{\mathrm{a}}$ & $0.873^{\mathrm{a}}$ \\
& PValue (2-tailed) & $<0.001$ & $<35^{\mathrm{a}}$ & $<0.001$ \\
\hline
\end{tabular}

Abbreviations: CBCTWL, cone beam computed tomography working length; EWL, electronic working length; RWL, radiographic working length.

${ }^{a}$ Confidence interval was determined at the 0.01 level (2-tailed).

\section{Acknowledgments}

There is no acknowledgment.

\section{Footnotes}

Authors' Contribution: Cihan Yildirim, study concept and design, drafting of the manuscript; Ali Murat Aktan, drafting and writing of the manuscript; Emrah karataslioglu, contributed to the development of the study pro- tocol, statistical analysis performance; Fatih Aksoy, contributed to the development of the protocol and abstracted data; Ozlem Isman, contributed to the development of the protocol and abstracted data; Emre Culha, developed the original idea and the protocol, study concept and design.

Financial Disclosure: Authors declared that there were no conflicts of interest related to the present survey.

Funding/Support: None declared. 


\section{References}

1. Ricucci D. Apical limit of root canal instrumentation and obturation, part 1. Literature review. Int Endod J. 1998;31(6):384-93. [PubMed: 15551606].

2. Nehammer CF. Treatment of the emergency patient. Br Dent $J$. 1985;158(7):245-54. [PubMed: 3857927].

3. ElAyouti A, Weiger R, Lost C. Frequency of overinstrumentation with an acceptable radiographic working length. JEndod. 2001;27(1):49-52. doi: 10.1097/00004770-200101000-00018. [PubMed:11487165].

4. Ravanshad S, Adl A, Anvar J. Effect of working length measurement by electronic apex locator or radiography on the adequacy of final working length: a randomized clinical trial.JEndod. 2010;36(11):1753-6. doi: 10.1016/j.joen.2010.08.017. [PubMed: 20951282].

5. Vieyra JP, Acosta J. Comparison of working length determination with radiographs and four electronic apex locators. Int Endod J. 2011;44(6):510-8. doi: 10.1111/j.1365-2591.2011.01855.x. [PubMed: 21306402].

6. Nekoofar MH, Ghandi MM, Hayes SJ, Dummer PM. The fundamental operating principles of electronic root canal length measurement devices. Int Endod J. 2006;39(8):595-609. doi: 10.1111/j.13652591.2006.01131.x. [PubMed: 16872454].

7. Kobayashi C, Suda H. New electronic canal measuring device based on the ratio method. J Endod. 1994;20(3):111-4. doi: 10.1016/S00992399(06)80053-1. [PubMed: 7996080].

8. Wenzel A. A review of dentists' use of digital radiography and caries diagnosis with digital systems. Dentomaxillofac Radiol. 2006;35(5):307-14. doi: 10.1259/dmfr/64693712. [PubMed: 16940477].

9. Real DG, Davidowicz H, Moura-Netto C, Zenkner Cde L, Pagliarin $\mathrm{CM}$, Barletta FB, et al. Accuracy of working length determination using 3 electronic apex locators and direct digital radiography. Oral Surg Oral Med Oral Pathol Oral Radiol Endod. 2011;111(3):e44-9. doi: 10.1016/j.tripleo.2010.10.033. [PubMed: 21310349].

10. Cianconi L, Angotti V, Felici R, Conte G, Mancini M. Accuracy of three electronic apex locators compared with digital radiography: an ex vivo study.JEndod. 2010;36(12):2003-7. doi:10.1016/j.joen.2010.08.036. [PubMed: 21092822].

11. Mancini M, Felici R, Conte G, Costantini M, Cianconi L. Accuracy of three electronic apex locators in anterior and posterior teeth: an ex vivo study. J Endod. 2011;37(5):684-7. doi: 10.1016/j.joen.2011.02.011. [PubMed: 21496671].

12. Stoll R, Urban-Klein B, Roggendorf MJ, Jablonski-Momeni A, Strauch $\mathrm{K}$, Frankenberger R. Effectiveness of four electronic apex locators to determine distance from the apical foramen. Int Endod J. 2010;43(9):808-17. doi: 10.1111/j.1365-2591.2010.01765.x. [PubMed: 20796049].

13. Venturi M, Breschi L. A comparison between two electronic apex locators: an in vivo investigation. Int Endod J. 2005;38(1):36-45. doi: 10.1111/j.1365-2591.2004.00899.x. [PubMed: 15606822].

14. Quereshy FA, Savell TA, Palomo JM. Applications of cone beam computed tomography in the practice of oral and maxillofacial surgery. $J$ Oral Maxillofac Surg. 2008;66(4):791-6. doi: 10.1016/j.joms.2007.11.018. [PubMed: 18355607].

15. De Vos W, Casselman J, Swennen GR. Cone-beam computerized tomography (CBCT) imaging of the oral and maxillofacial region: a systematic review of the literature. Int J Oral Maxillofac Surg. 2009;38(6):609-25. doi: 10.1016/j.ijom.2009.02.028. [PubMed: 19464146].

16. Ludlow JB, Ivanovic M. Comparative dosimetry of dental CBCT devices and 64-slice CT for oral and maxillofacial radiology. Oral Surg Oral Med Oral Pathol Oral Radiol Endod. 2008;106(1):106-14. doi: 10.1016/j.tripleo.2008.03.018. [PubMed: 18504152].

17. Schulze D, Heiland M, Thurmann H, Adam G. Radiation exposure during midfacial imaging using 4- and 16-slice computed tomography, cone beam computed tomography systems and con- ventional radiography. Dentomaxillofac Radiol. 2004;33(2):83-6. doi: 10.1259/dmfr/28403350. [PubMed: 15313998].

18. Alamri HM, Sadrameli M, Alshalhoob MA, Sadrameli M, Alshehri MA. Applications of CBCT in dental practice: a review of the literature. Gen Dent. 2012;60(5):390-400. [PubMed: 23032226] quiz 401-2.

19. Durack C, Patel S. Cone beam computed tomography in endodontics Braz Dent J. 2012;23(3):179-91. [PubMed: 22814684].

20. Connert T, Hulber JM, Godt A, Lost C, ElAyouti A. Accuracy of endodontic working length determination using cone beam computed tomography. Int Endod J. 2014;47(7):698-703. doi: 10.1111/iej.12206. [PubMed: 24134733].

21. Baumgaertel S, Palomo JM, Palomo L, Hans MG. Reliability and accuracy of cone-beam computed tomography dental measurements. Am J Orthod Dentofacial Orthop. 2009;136(1):19-25.

22. Lucena C, Lopez JM, Martin JA, Robles V, Gonzalez-Rodriguez MP. Accuracy of working length measurement: electronic apex locator versus cone-beam computed tomography. Int Endod J. 2014;47(3):246-56. doi: 10.1111/iej.12140. [PubMed: 23772839].

23. Liang YH, Jiang L, Chen C, Gao XJ, Wesselink PR, Wu MK, et al. The validity of cone-beam computed tomography in measuring root canal length using a gold standard. J Endod. 2013;39(12):1607-10. doi: 10.1016/j.joen.2013.08.001. [PubMed: 24238457].

24. Tchorz JP, Poxleitner PJ, Stampf S, Patzelt SB, Rottke D, Hellwig E, et al. The use of cone beam computed tomography to predetermine root canal lengths in molar teeth: a comparison between two-dimensional and three-dimensional measurements. Clin Oral Investig. 2014;18(4):1129-33. doi: 10.1007/s00784-013-1064-6. [PubMed: 23896729].

25. Ozsezer E, Inan U, Aydin U. In vivo evaluation of ProPex electronic apex locator. J Endod. 2007;33(8):974-7. doi: 10.1016/j.joen.2007.04.003. [PubMed: 17878086].

26. Ricard O, Roux D, Bourdeau L, Woda A. Clinical evaluation of the accuracy of the Evident RCM Mark II Apex Locator.JEndod. 1991;17(11):567-9. doi:10.1016/S0099-2399(06)81723-1. [PubMed:1812206].

27. Dummer PM, McGinn JH, Rees DG. The position and topography of the apical canal constriction and apical foramen. Int Endod J. 1984;17(4):192-8. [PubMed: 6593303].

28. Saatchi M, Aminozarbian MG, Hasheminia SM, Mortaheb A. Influence of apical periodontitis on the accuracy of 3 electronic root canal length measurement devices: an in vivo study. J Endod. 2014;40(3):355-9. doi: 10.1016/j.joen.2013.11.012. [PubMed: 24565652].

29. da Silva TM, Alves FR. Ex vivo accuracy of Root ZX II, Root ZX Mini and RomiApex A-15 apex locators in extracted vital pulp teeth. J Contemp Dent Pract. 2014;15(3):312-4. [PubMed: 25307812].

30. Saatchi M, Rahimi I, Khademi A, Farhad AR, Nekoofar MH, Dummer PM. Influence of tooth length on the accuracy of the Root ZX electronic apical foramen locator: an ex vivo study. Acta Odontol Scand. 2015;73(2):101-6. doi: 10.3109/00016357.2014.956144. [PubMed: 25299599].

31. Akisue E, Gratieri SD, Barletta FB, Caldeira CL, Grazziotin-Soares R, Gavini G. Not all electronic foramen locators are accurate in teeth with enlarged apical foramina: an in vitro comparison of 5 brands. J Endod. 2014;40(1):109-12. doi: 10.1016/j.joen.2013.09.032. [PubMed: 24332000].

32. Duran-Sindreu F, Gomes S, Stober E, Mercade M, Jane L, Roig M. In vivo evaluation of the iPex and Root ZX electronic apex locators using various irrigants. Int Endod J. 2013;46(8):769-74. doi: 10.1111/iej.12057. [PubMed: 23551276].

33. Ustun Y, Uzun O, Er O, Canakci BC, Topuz O. The effect of residual calcium hydroxide on the accuracy of a contemporary electronic apex locator. Acta Odontol Scand. 2015;73(2):132-6. doi: 10.3109/00016357.2014.961027. [PubMed: 25247720].

34. Ebrahim AK, Yoshioka T, Kobayashi C, Suda H. The effects of file size, sodium hypochlorite and blood on the accuracy of Root ZX apex locator in enlarged root canals: an in vitro study. Aust Dent J. 2006;51(2):153-7. [PubMed: 16848263]. 
35. Gordon MP, Chandler NP. Electronic apex locators. Int Endod J. 2004;37(7):425-37. doi: 10.1111/j.1365-2591.2004.00835.x. [PubMed: 15189431].

36. Janner SF, Jeger FB, Lussi A, Bornstein MM. Precision of endodon- tic working length measurements: a pilot investigation comparing cone-beam computed tomography scanning with standard measurement techniques. J Endod. 2011;37(8):1046-51. doi: 10.1016/j.joen.2011.05.005. [PubMed: 21763892]. 